\title{
Pre-school children creating and communicating with digital technologies in the home
}

\author{
Joanna McPake, Lydia Plowman and Christine Stephen
}

Joanna McPake is Reader in the School of Education at the University of Strathclyde. Lydia Plowman is Professor and Christine Stephen Research Fellow at the School of Education at the University of Stirling. Together, we have undertaken three studies of pre-school children's experiences with digital technologies at home, addressing issues such as whether children from low income families are disadvantaged in this regard, how the acquisition of early digital literacies compares with traditional literacies and the characteristics of play with digital toys and games. An in-depth discussion of the findings from our first two studies can be found in Plowman, L., Stephen, C. and McPake, J. (2010a) Growing Up with Technology: Young children learning in a digital world (Routledge).

Address for correspondence:

Joanna McPake, School of Education, Faculty of Humanities and Social Sciences, University of Strathclyde, GLASGOW, G1 1XQ.

Email: joanna.mcpake@strath.ac.uk

\begin{abstract}
There is a limited literature on pre-school children's experiences with digital technologies at home and little discussion of the ways in which children harness these technologies for their own purposes. This paper discusses findings drawn from three studies which investigated the role of domestic technologies and digital toys and games in young children's lives. Specifically, it focuses on children's early communicative and creative experiences, concluding that digital technologies have the potential to expand young children's repertoire of activities in this context. It is therefore important that pre-school and early years specialists recognise and respond to the expertise children will have already developed by the time they enter formal education, given the increasing technologisation of communicative and creative activities, likely to continue over the lifecourse of those born at the start of the $21^{\text {st }}$ century.
\end{abstract}

\section{Practitioner notes}

What is already known about this topic

- Young children's emergent communicative and creative competences in the early years represent valuable starting points for their more formal developmentparticularly in the context of early literacy — when they start school.

\section{What this paper adds}

- This paper explores ways in which these developing competences are supported by domestic digital technologies - the wide and increasing range of technological tools, ranging from computers and mobile phones to MP3 players and technological toys and games-available in the home. 
- It concludes that digital technologies have the potential both to facilitate communicative and creative tasks and to expand young children's repertoires.

\section{Implications for practice and/or policy}

- Early years policy in the UK already draws attention to the need to build on the experiences children bring with them from home, including their experiences of using domestic digital technologies.

- Practitioners need to develop imaginative ways of responding to what children already know and can do with technology, in the context of communicating and creating.

\section{Introduction}

Having conducted research with families with children aged three to four since 2003, we have observed how the growth in domestic digital technologies has affected children's lives. We define these broadly, to include not only desktop and portable computers but also entertainment technologies such as modern multifunction TV sets, video gaming devices and music players, and mobile telephones. In our most recent field visits, in 2009, every participating family had at least one home computer and broadband access to the Internet. Each had at least one TV set, mobile phone and games console. Products bought specifically for children's use included DVDs, video games, MP3 players, still and digital cameras, mobile phones and electronic books as well as digital toys, such as dolls, animals or vehicles which can move, speak or make noises when triggered by the child. We refer to items specifically designed for children as digital toys and games. However, not all the items children possessed were toys or games: some acquired, new or second-hand, domestic technologies originally intended for adult use. Collectively, in this paper, we refer both to the domestic digital technologies in general use in the home and to the digital toys and games for young children as digital technologies, applying the more specific terms when appropriate.

While the last decade has seen a very significant expansion in the range of digital technologies available in people's homes, not all of these are radically new devices. Telephones and televisions have a long history in the home, and automata as toys can be traced back at least to the $19^{\text {th }}$ century. Our focus is not specifically on the most recent arrivals but rather on the increasingly large and diverse range of digital technologies available to children at the time of our research, and the nature of the experiences these afforded. Touch screen tablet devices, such as iPads and certain smart phones, which are also now widely available in homes, are not included in our discussions of the findings from our research as they were only beginning to appear when our most recent field visits concluded in 2009. Nevertheless, the exponential growth and increasing sophistication of digital technologies found in homes across the UK over the course of the last decade meant that by the time they started school (typically, in Scotland, between the ages of 4 years 6 months and 5 years 6 months), the children in our studies had already had extensive exposure, considerably greater than had been the case for their counterparts only a decade earlier.

\section{The contribution made by our research}

The research presented here is innovative in that it addresses the experiences of preschool children, using a qualitative approach which draws on socio-cultural theory to identify the ways in which their early experiences with digital technologies are shaping 
their communicative and creative practices. The conclusions which we draw - that digital technologies have the potential to expand young children's communicative and creative repertoires - have significant implications for early years education, where practitioners are asked to build on what children bring from home and need therefore to take into account the ways in which the home environment is changing as a result of the rapidly growing presence of digital technologies, and consequently also the nature of children's experiences and the practices they develop as a result. In all of these aspects - focus, methods and findings - this research breaks new ground in understanding the nature and educational consequences of young children's experiences with digital technologies.

There is a growing literature (cf. Buckingham and Willet, 2006; Carrington and Robinson, 2009; Ito, 2010) on the educational implications for children, typically considered enthusiastic consumers of screen-based entertainment and digital communications ranging from texting to social networking sites. However, this has mainly addressed children over five years old. The literature on preschool children is limited and often discursive rather than evidence-based. There has been very little of the kind of detailed, qualitative research we describe here. Although some large-scale surveys concerning children's experiences with digital technologies have included preschoolers (eg. Rideout and Kaiser Family Foundation, 2007), these tend to link data on ownership and use of technological items to hypotheses about their effects. Our research in children's homes indicates that the situation is more complex and varied than can be revealed by such surveys.

Our research questions, methods and analytical approaches have been influenced by socio-cultural perspectives: the mediation of learning through children's use of tools and artefacts, their interactions with adults or more able peers, and the culturally and historically defined social situation of the child's learning circumstances (Vygotsky, 1962, 1978; Rogoff, 1990, 2003). Hedegaard (2009) extended this concern with the social context of learning to consider the relationship between the child and institutional practices, including those of the home where they are growing up. She argues that these practices are shaped by adults' values and beliefs but also that children's interactions in any context are mediated through their own motives and preferences. Thus our research into children's experiences of digital technologies at home focuses on the kinds of technologies they encounter, interactions around these technologies and ways in which the home environment shapes and is shaped by these encounters and interactions.

\section{Children creating and communicating}

This paper discusses findings relating to children's early communicative and creative experiences with digital technologies in the home, because these are regarded as key areas of children's development in the period leading up to their entry into formal education, with significant implications in particular (but not only) for subsequent progress in literacy (Anning \& Edwards, 2006; Nutbrown, 2006; Duffy, 2006). Traditionally, research into the development of communicative competences focused on spoken language acquisition and early literacy. More recent work has drawn attention to the need now to encompass a wider range of communicative means, including still and moving visual communication, dance, music and gesture (Kress, 2003; Lankshear and Knobel, 2006; Wolfe and Flewitt, 2010). These occur separately and in combination - ie. multimodally across a variety of media platforms, ranging from traditional oral communication and written texts, to screen-based media, including TV, computers, games-consoles and touch-screens. Understanding ways in which children develop communicative 
competences across these media includes: attention to acquisition of the operational skills for communication (such as the prosody of spoken language, symbol recognition and reproduction in written language, or keyboard or camera controls); the purposes of communication; cultural conventions (such as politeness, turn-taking, narrative structures); and an understanding of audience. These are all issues to be examined when investigating ways in which young children learn to communicate with digital technologies, though to date, the focus has largely been on acquisition of operational skills, with limited attention to other aspects.

Duffy (2006, p. xvi) notes that the importance of promoting creativity in the early years, particularly through participation in visual and performing arts, has only relatively recently been recognised. Its relevance to learning lies in particular in encouraging discovery, exploration, experimentation and invention. Indeed, Boden (2004, p. 1) defines creativity as "the ability to come up with ideas or artefacts that are new, surprising, and valuable." She argues that creative practices or behaviours are part of the general system of intelligence shared by all, "grounded in everyday abilities such as conceptual thinking, perception, memory, and reflective self-criticism" (op. cit., p. 1). Building on Boden's definition, Ackermann, Gauntlett, Wolbers and Weckström (2009) consider ways in which children's curiosity and playfulness enable them to engage in the kinds of behaviours they see as critical to the creative process: combining ideas in new ways, exploring, and transforming the way we see the world.

Much discussion of culture and creativity in the early years looks for universals. However, in keeping with our socio-cultural frame, we share conclusions drawn by Faulkner, Coates, Craft and Duffy (2006) in their review of research in this field, that "culture and creativity should be regarded as socially constructed, dynamic dimensions of children's activities and socialization that emerge through interactions with other people and with the environment" (p. 191). Clearly, the growing presence of digital technologies in young children's homes is likely to influence the development of creative behaviours, through the stories and role-play games they construct in response to films or video games, the use of still and video cameras to document their own perspectives on the world, or music and dance performances facilitated by music technologies such as MP3 players, karaoke machines or dance mats. The ways in which children use these technologies, the kinds of interactions they have with others about them and the possibilities and limitations imposed by the home environment will all have a bearing.

In this paper, we consider the role that digital technologies may play in supporting and enhancing young children's developing communicative and creative competences by drawing on our three studies to address the following questions:

1. What are children learning about the roles digital technologies play in supporting communication and creativity in their families and communities?

2. To what extent are they able to harness these technologies for their own purposes?

3. What use will they make of their knowledge and experiences when they start school?

\section{Methods}

The first of our three studies, Already at a Disadvantage? took place over seven months, from 2003-2004. This was a pilot study based principally on case-studies of eight 
'disadvantaged' and eight 'more advantaged' children and their families. It set out to investigate the impact of socio-economic disadvantage on pre-school children's developing technological competences, and found that the concept of digital divides was more complex than had previously been thought. It had been assumed that children from young disadvantaged families would have limited opportunities to make use of digital technologies had home, but this study showed that, in different ways, all the participating families enabled their children to explore a range of digital technologies for a variety of purposes, including communications and creative activities.

The second study, Entering e-Society, funded by the Economic and Social Research Council (ESRC), was longitudinal, following 11 'disadvantaged' and 13 'more advantaged' children over 18 months in 2005-2007, by which time most had started school. It investigated the effects of socio-economic disadvantage on children's early learning with digital technologies and implications for subsequent educational development. A specific focus of this study was on children's developing e-literacy, i.e. on how they learned to use digital technologies for communicative purposes, taking advantage of greater opportunities for multimedia and multimodal communications. The study compared young children's communicative competences deriving from activities associated with digital technologies and those from traditional early literacy activities, such as looking at printed books, drawing with crayons on paper, or listening to stories read aloud by an older family member or friend.

Our most recent study, Young Children learning with Toys and Technology, also funded by the ESRC, took place over 36 months, from 2008-2011. It involved 14 families, with seven categorised in terms of the parents' employment and education as being of low socioeconomic status. The resulting household case-studies constitute a richly detailed account of young children's encounters with the full range of domestic, leisure and work technologies at home, including technological toys. This study investigated children's play- with both technological and traditional toys - and how this relates to learning. Over the three studies, we identified a range of types of learning to which digital technologies contribute: operational skills (learning how to use both traditional and technological tools such as pencils, on/ off switches, books or DVDs), knowledge and understanding of the world (ranging from learning to count or recognise the shapes of letters to finding out about dinosaurs or volcanoes), dispositions to learn (e.g. persistence, concentration, confidence) and learning about the role of technologies in daily life (e.g. their use in supporting communications, shopping or leisure activities). In this paper, we focus on the kinds of play and learning activities which relate to developing communicative and creative competences, drawing on relevant findings from all three studies.

Across these three studies, we have worked closely with 54 families, recruited via nurseries in central Scotland and selected to ensure a balanced distribution of gender of the target child and family socio-economic status (SES).

Although case study-based research, is, by nature, small-scale, multiple rounds of data collection over the course of the past eight years have enabled us to build up a detailed picture over a relatively long period of time, of the ways in which young children engage with digital technologies at home and in the context of their family lives. All of our studies have considered the range of technologies available to children at home, how children made use of the resources available, and how their families supported this. The cases are representative in that they highlight some of the complexities of children's 
experiences with technologies at home but we do not claim generalisability for these findings because the particular configurations of socio-economic status, availability of different types of technology and attitudes and experiences were unique. Flyvbjerg (2006) addresses this issue in his discussion of common misunderstandings about case-study research, asserting the value of a descriptive case-study in the process of knowledge accumulation.

One key feature of our work is the recognition that the environment itself is an agent in shaping learning interactions (McPake, 2010; Plowman et al. 2010b). The three studies are therefore linked by a perspective which highlights the interactions between people, places and things, and their relationship to the values and practices that permeate family life and everyday activities.

Our visits enabled us to develop relationships of trust, gain an understanding of family lives and cultures, and thus to engage in a range of data collection exercises which included but went beyond standard interviews: for example, videos of day-to-day life recorded by the families; audits of the toys and technologies found at home; a range of strategies designed to elicit children's perspectives on their experiences (Stephen $e t$ al. 2008), including inviting children to conduct tours of their own homes, identifying features of significance to them (Stevenson \& Adey 2010); and mobile phone diaries which documented children's activities over the course of specified days (Plowman $\&$ Stevenson, forthcoming).

Findings from all three studies, relating to young children's experiences of using digital technologies to communicate and create, are presented below. Vignettes (short illustrations), based on our case-study families, exemplify these experiences. The names of case-study participants and the places where they lived are pseudonyms.

\section{What are children learning about the roles digital technologies play in supporting communication and creativity in their families and communities?}

Just as young children learn how and why to speak by observing and interacting with adults and older siblings, they also learn how and why to use different communication technologies by observing the ways in which others make use of them, and trying out such activities themselves. For example, on one of our field visits, we observed a ninemonth-old baby (brother to the child in our study) pick up a toy mobile phone and 'talk' into it, even although he had only reached the babbling stage and had no recognisable words: Duncan already knew that mobile phones were a significant feature in his home and that they were used for communicating - and he wanted to participate in this activity, even though he himself could not yet talk.

By the time they were three or four years old, children in our studies were aware not only of the role of speech but also of the written language in their environment. In debates around the value of learning to use digital technologies in the early years, it is often argued that too early or too extensive an exposure to television and computers may hinder children's development of 'traditional' (paper-based) literacies (Miller, 2005; but see also Eagle, 2012), or that early years practitioners, lacking confidence in the use of digital technologies in pre-school settings, are concerned that this might be the case (Chen \& Chang, 2006; Plowman \& Stephen, 2005). However, our research indicates that 'traditional' and 'digital' experiences are not so neatly segregated. Watching a programme on TV can lead to a desire to be read related stories in books or magazines, and to play 
with toy characters based on the programme as well as online video games on the broadcaster's website. The desire to learn more about a favourite TV series or other topics of interest first encountered on screen can fuel the motivation to learn to read oneself, as Allan's story reveals:

\begin{abstract}
Allan: TV enthusiast and early reader
Allan was three years old when we first visited his family. His parents had just acquired SkyPlus on their TV, and he had become fascinated by options for storing and retrieving programmes and planning future viewing, using the onscreen TV guide. On our first visit, he could identify the names of his favourite programmes. Five months later he could read through the guide and was learning to tell the time in order to know when programmes he wanted to watch would be on. He progressed to reading TV listings in newspapers and TV guide magazines. "People say you shouldn't let your children watch TV, but it's taught Allan a lot," his mother commented.
\end{abstract}

We observed how children's play activities incorporated technologies, demonstrating that they saw technological tools as part of their everyday environment and understood their purposes, even when they were not necessarily able to use them fully themselves. For example, they used old computers, non-functioning mobile phones and toy replicas of technological items, such as supermarket scanners or laptops, as props for imaginative games involving work in imaginary homes, shops or schools:

\title{
Hannah: playing the role of school pupil
}

Three-year-old Hannah lived with her parents and older sister Sarah, aged eight. The family had two computers, one in the living room, intended mainly for adult use, and an older computer in Sarah's bedroom. The older computer was rarely switched on but served as an important role-play prop in which Sarah took on the role of primary school teacher and Hannah one of her pupils. Drawing on her experience of computers at school, Sarah devised imaginary activities where Hannah had to draft work on the computer and communicate with children in other countries. Hannah would tap enthusiastically at the keyboard while Sarah corrected her work and read out the messages other children had supposedly sent.

\section{To what extent are children able to harness these technologies for their own purposes?}

Digital technologies have thus greatly expanded the visibility and accessibility of graphic and written communication in children's lives. Opportunities to see this form of communication in action are increased by family and friends' frequent use of texting and other screen-based communications, and possibilities for young children to participate themselves are enhanced by the multimodality of such communications, using visual symbols, photographs, video and sound as well as written texts. These additional elements can make it easier for children to understand who is communicating and why, and to reply: if they cannot yet write a message, they can add a photo or a smiley face, or participate in making a video they know will be sent to distant relatives. In this way, they become part of social networks outside their immediate community at an earlier age and in more proactive ways than might have been possible even a decade ago. 


\section{Colin: photographer}

Most children had extensive experience of being photographed and videoed, from babyhood onwards, and some were beginning to use digital cameras to record and communicate their own perspectives. Colin was three years old when we visited his family, and already a proficient photographer. He was learning to store and retrieve photos electronically, with help from his mother. On later visits, we found that Colin and Emma, his five-year-old sister, were communicating with relatives in Australia, sending them photographs and messages containing emoticons (neither could write at this stage) and using a webcam for video calls.

Colin's story shows several features of communicative competence in development: operational skills (such as taking, storing, retrieving and sending photographs), learning about the purposes of communication (building and maintaining social ties, in this case), about cultural conventions (choosing the most appropriate photographs to send) and about the need to understand the audience's point of view (learning, for example, that the Australian relatives needed explanations because his familiar world was strange to them). In earlier times, traditional literacy practices would similarly have helped Colin to develop these competences, particularly if his mother and their Australian relatives had been prolific letter-writers and had provided opportunities for Colin to include drawings and early attempts at writing. But it seems unlikely that these experiences could have supported the rapid development of competences afforded by the combination of synchronous and asynchronous, multimodal and multimedia communications, or that Colin and Emma would have become quasi-autonomous interlocutors, given the likely limitations of communications of paper-based literacies alone.

Colin's story also reveals emerging creative behaviours supported by the technologies to which he had access. As noted earlier, creativity in the early years involves exploration, and the ability to come up with new, surprising and valuable ideas. Colin took thousands of photographs, in the house and the surrounding area. Though this process of exploration, -unrestricted (to begin with) by any notions of photographic conventions, or understanding of the limitations of the camera - he tried to take photographs of things which would, to adult eyes, be surprising photographic subjects: for example, he attempted to photograph the insides of his dog. Through experience, particularly of the need to select photographs and by viewing photographs taken by others, he learned more about the conventions of visual communication. But he also learned more about telling a story in visually meaningful and engaging ways, beginning to develop the skills to create new and (socially) valuable narratives.

Other children found ways of using existing images to enhance their imaginative play, similarly developing the ability to embellish existing narratives and create their own.

\section{Liam: puppeteer}

Liam, a quiet four-year-old boy, was enthusiastic about the film of The Lord of the Rings, and played various imaginative games based on this. He searched the web for pictures of his favourite characters. His father printed them on glossy paper and his mother cut them out and stuck them on card. Liam then used these cardboard cutouts as puppet figures in games he invented himself.

In earlier times, Liam could have engaged in similar activities without technological support. In the pre-digital age, children encountered myths and legends through oral story-telling and books. They also retold and reinvented these stories (ie. combined and 
transformed them) through imaginative play, dressing up as the characters, using puppets or illustrating the story through drawings. Liam's story shows how technologies can enhance these experiences. Firstly the film made a long and challenging narrative accessible: through repeated DVD viewings, he became familiar with the characters and the elements of the story. Secondly, the availability via the Internet of still photographs from the film meant that Liam could choose those he preferred and indeed have several versions of the principal characters, in different clothes and poses, depending on the part of the story he chose to re-enact. These allowed Liam to construct new narratives, based on, but not tied to, different stages of the film.

Music is another medium through which young children have opportunities to develop creative behaviours. As Young (2009) has noted, the growing range and ubiquity of music technologies have significantly changed and expanded children's experiences of listening to music and creating and performing music at home.

\footnotetext{
Kylie: singer

Kylie's mother was a keen singer and bought Kylie, aged three, a sophisticated karaoke machine as a Christmas present. She encouraged Kylie to sing along with the backing tracks. She had several tapes (mainly of nursery rhymes) and sang with great enthusiasm. Her mother often invited others to their house and adults and children spent evenings singing together. These activities helped develop Kylie's musical abilities and her sense of audience, and also alleviate the social isolation which Kylie and her mother, a young lone parent, had been experiencing.
}

Karaoke machines might be considered to constrain children's creativity: they determine which songs can be sung, on the basis of the tracks available, and which versions. However they can also be seen as extending the repertoire by introducing previously unknown songs to the family, and encouraging singers to focus on aspects of performance which might once have been less salient, such as keeping time, use of dynamics, responsiveness to audience. Karaoke machines are perhaps particularly valuable in families without much experience or skill in singing, playing and performing. Along with MP3 players and digital musical instruments, they extend opportunities for children to explore music, develop competence and create new forms of their own, just as the digital camera extends opportunities for visual expression and the multimedia guises of stories such as The Lord of the Rings for narrative expression.

\section{What use will they make of their knowledge and experiences when they start school?}

It is now well-established that children's early experiences play an important role when they start formal learning at school. How do their experiences with digital technologies fit into this picture? Table 1 compares the kinds of pre-school communicative and creative competences children were expected to develop in traditional contexts - i.e. before the widespread use of home technologies - and parallels we have identified in digital homes. 
Table 1: Comparing traditional and digital communicative and creative competences in the early years

Traditional examples Technical skills to support
communicative practices

Competence in communicating over time and distance

Exploring, combining and transforming narrative expression

Exploring, combining and Symbols, drawings, paintings transforming visual expression

Exploring, combining and transforming musical expression
Shapes and sounds of letters, holding a pencil or a book, alphabet and spelling games

Letters, postcards, birthday cards

Listening to stories, telling stories

Listening to others sing and play instruments live, learning and performing familiar songs, making up own songs and music (with traditional instruments, including toy versions, where available)
Digital examples

Main functions of different technologies (off, on, fast forward, alert sounds), keyboard symbols (recognition and location), using a mouse

Text messages, email, sending and receiving digital photographs

Watching TV/DVDs, engaging with interactive digital storybooks or websites; acting scenes from favourite programmes or films

Emoticons, taking and editing photographs and videos

Listening to music from a variety of digital sources (eg, radio, TV, MP3 players, YouTube), learning and performing familiar songs, making up own songs and music (with electronic instruments, including toy versions, where available

This comparison suggests that communicative and creative activities stimulated by digital technologies complement those children are developing as a result of other more traditional early experiences. Long-standing childhood practices such as listening to stories, singing nursery rhymes, drawing, making greetings cards, and imagining their own adventures, with the help of props such as dressing up clothes, toy musical instruments or paints, contribute to their interest and understanding of narratives, song and graphic representation. Watching TV programmes and films, singing along with a karaoke machine, taking photographs and sending them as picture messages, and imagining their own adventures with technological props - mobile phones, electronic wands, toys which walk and talk - develop similar skills from an expanded range of sources and often for a wider audience, given the increased potential to communicate over a distance.

\section{Conclusion}

Children's experiences in the early years play an important part in the development of communicative and creative competences. As we have seen from the discussion above, young children are learning about the roles digital technologies can play in supporting communicative and creative activities, from the ways in which family and friends make use of them and from the opportunities they themselves have had to explore the potential of different technological tools, along with the traditional tools which have long been at their disposal. As is the case for adults, these expand the repertoire of possibilities for young children to communicate and create and can also make some tasks less repetitive or more intuitive. In our studies, which set out to explore and describe the range of experiences young children have with digital technologies at home, opportunities to make detailed comparisons between traditional and digital tools in 
relation to the processes and outcomes of such activities were limited: future research could investigate specific elements of children's developing communicative and creative competences (e.g. the purposes of communication; an understanding of audience; the combining of ideas in new ways; exploring or transforming the way we see the world), focusing on ways in which digital technologies may facilitate the task and expand the repertoire in each of these areas.

The competences children have developed at home will be of great value when they start school and begin the formal processes of learning to communicate, explore the creations of others (stories, plays, art, music) and express their own ideas creatively. Many of the children now attending pre-school and the early years of primary education have grown up in homes where multimedia, multimodal forms of expression are common and their experiences of using digital technologies for communicative and creative purposes can be extensive. Early years policy in the UK already recognises the importance of building on these experiences when children start formal education: for example, the Early Level of Curriculum for Excellence in Scotland lists as desirable experiences and outcomes that young children should enjoy 'exploring and using technologies to communicate with others within and beyond [their] place of learning'; and 'taking photographs or recording sound and images to represent [their] experiences and the world around [them]' (Learning \& Teaching Scotland, no date: p4). For practitioners, responding imaginatively to the expanded range of competences children bring to school will become increasingly critical, both in meeting enhanced expectations born of these early experiences, and recognising that the communicative and creative landscape in which today's children will operate in ten or twenty years time will reflect and reward the opportunities and encouragement on offer in the education system now.

\section{Acknowledgements}

Several researchers collaborated with us on each of the studies reported here and we gratefully acknowledge the very valuable contributions of Claire Adey, Sarah BerchHeyman, Alan Prout, Daniela Sime and Olivia Stevenson at different stages of the research.

\section{References}

Ackermann, E., Gauntlett, D., Wolbers, T. \& Weckström, C. (2009). Defining Systematic Creativity in the Digital Realm. Slough: Lego Learning Institute.

Anning, A. \& Edwards, A. (2006). Promoting Children's Learning from Birth to Five: Developing the new early years professional. ( $2^{\text {nd }}$ Edn.) Maidenhead: Open University Press.

Boden, M. (2004). The Creative Mind: Myths and Mechanisms. ( $2^{\text {nd }}$ Edn.) London: Routledge.

Buckingham, D. \& Willet, R. (2006). Digital Generations: Children, young people, and new media. London: Routledge.

Carrington, V. \& Robinson, M. (2009). Digital Literacies: Social Learning and Classroom Practices. London: Sage.

Chen, J. \& Chang, C. (2006). Using Computers in Early Childhood Classrooms: Teachers' attitudes, skills and practices. Journal of Early Childhood Research 4(2), 169188.

Duffy, B. (2006). Supporting Creativity and Imagination in the Early Years. $\left(2^{\text {nd }}\right.$ Edn.) Maidenhead: Open University Press.

Eagle, S. (2012). Learning in the early years: Social interactions around picturebooks, puzzles and digital technologies. Computers \& Education, 59 (1), 38-49. 
Faulkner, D., Coates, E., Craft, A. \& Duffy, B. (2006). Creativity and cultural innovation in early childhood education. International Journal of Early Years Education. 14 (3), 191 199.

Flyvbjerg, B. (2006). Five Misunderstandings about Case-Study Research. Qualitative Research. 12 (2), 291-245.

Hedegaard, M. (2009). Children's Development from a Cultural-Historical Approach: Children's activity in everyday local settings as foundation for their development. Mind, Culture, and Activity, 16 (1), 64-82.

Ito, M. (2010). Hanging Out, Messing Around and Geeking Out: Kids living and learning with new media. Cambridge, MA: MIT Press.

Kress, G. (2003). Literay in the New Media Age. London: Routledge.

Lankshear, C. \& Knobel, M. (2006). New Literacies: Everyday Practices and Classroom Learning. 2nd edition. Maidenhead: Open University Press.

Learning \& Teaching Scotland (no date). Curriculum for Excellence: Technologies. Experiences and Outcomes. Glasgow: Learning \& Teaching Scotland. Available at: http://www.ltscotland.org.uk/learningteachingandassessment/curriculumareas/tech nologies/eandos/index.asp. (Accessed 2 December 2011.)

McPake J. (2010). The home as a technological learning environment: children's early encounters with digital technologies. Paper presented at the American Educational Research Association (AERA) Conference, Denver, April 30-May 2.

Miller, E. (2005). Fighting technology for toddlers. Education Digest 71(3), 55-58.

Nutbrown, C. (2006). Threads of Thinking: Young children learning and the role of early education. $\left(3^{\text {rd }} \mathrm{Edn}\right.$.) London: Sage.

Plowman L. \& Stephen, C. (2005). Children, play, and computers in pre-school education. British Journal of Educational Technology 36(2), 145-157.

Plowman L., Stephen C. \& McPake, J. (2010a). Growing Up with Technology: Young children learning in a digital world. London: Routledge.

Plowman L., Stephen C. \& McPake, J. (2010b). Supporting young children's learning with technology at home and in preschool. Research Papers in Education, 25 (1), 93-113.

Plowman, L. \& Stevenson, O. (forthcoming). Using mobile phone diaries to explore children's everyday lives. Childhood.

Rideout, V. \& Kaiser Family Foundation (2007). Parents, Children and Media: A Kaiser Family Foundation survey. Menlo Park, CA: Kaiser Family Foundation.

Rogoff, B. (1990). Apprenticeship in Thinking: Cognitive development in social context. New York: Oxford University Press.

Rogoff, B. (2003). The Cultural Nature of Human Development. New York: Oxford University Press.

Stephen C., McPake J., Plowman L. \& Berch-Heyman S. (2008) Learning from the children: exploring preschool children's encounters with ICT at home. Journal of Early Childhood Research 6, 99-117.

Stevenson O. \& Adey C. (2010) Toy tours: reflections on walking-whilst-talking with young children at home. Qualitative Researcher 12, 8-10.

Vygotsky, L. (1962). Thought and Language. Cambridge, MA: MIT Press.

Vygotsky, L. (1978). Mind in Society: The development of higher psychological processes. Cambridge, MA: Harvard University Press.

Wolfe, S. \& Flewitt, R. (2010). New technologies, new multimodal literacy practices and young children's metacognitive development. Cambridge Journal of Education. 40 (4), 387-399.

Young, S. (2009). Towards constructions of musical childhoods: Diversity and digital technologies. Early Child Development and Care. 179 (6), 695-705. 